\title{
Autonomy, depression and affecting factors in the elderly people
}

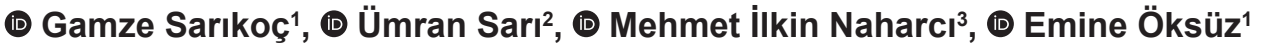 \\ 1 University of Health Sciences Turkey, Gülhane Faculty of Nursing, Department of Psychiatric Nursing, Ankara, Turkey \\ ${ }^{2}$ Guven Hospital, Clinic of Heart Vascular and Surgery, Ankara, Turkey \\ 3University of Health Sciences Turkey, Gülhane Faculty of Medicine and Gülhane Training and Research Hospital, Division of \\ Geriatrics, Ankara, Turkey
}

Date submitted:

12.02.2020

Date accepted:

02.06.2020

Online publication date:

15.12.2020

\section{Corresponding Author:}

Gamze Sarıkoç PhD, Assistant

Professor, University of Health

Sciences Turkey, Gülhane Faculty of

Nursing, Department of Psychiatric

Nursing, Ankara, Turkey

gamze.sarikoc@sbu.edu.tr

ORCID:

orcid.org/0000-0003-1651-4308

Keywords: Elderly, autonomy, depression

\section{ABSTRACT}

Aims: This study aimed to investigate the relationship between autonomy and depression in individuals older than 65 years and to evaluate the factors affecting these variables.

Methods: This study was conducted at the geriatric outpatient clinic of Gülhane Training and Research Hospital. The sample of the study consisted of 101 patients over 65 years of age, the ability to evaluate the truth was not impaired, there was no diagnosis of mental illness, and they accepted to participate in the study. The data were collected by using the "Descriptive Information Form", "The Functional Autonomy Measurement System-SMAF" and "Geriatric Depression Scale".

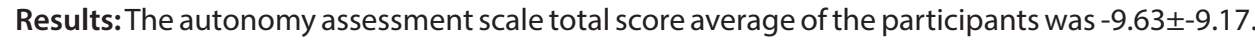
The mean total score of geriatric depression was 11.15 \pm 7.25 . There was a negative correlation between geriatric depression scale mean scores and autonomy assessment scale mean scores of elderly individuals and this relationship was statistically significant.

Conclusions: It was found that individuals over 65 years of age were at risk of losing their functional independence and that they had possible depression. Decreased functional independence increases with age and elevates the risk of depression in elderly individuals.

\section{Introduction}

The population aged 65 years and over is increasing all over the World (1). In Turkey, the elderly population was 5 million 891 thousand 694 people in 2013 and increased by $17 \%$ in the last five years and became 6 million 895 thousand 385 people in 2017 . While the ratio of the elderly population in the total population was $7.7 \%$ in 2013 , it increased to $8.5 \%$ in 2017 (2). High life expectancy and economic burdens may pose a problem for the health system that best serves elderly adults with chronic diseases and high risk of hospitalization (3). Prolongation of the life span and physical, sensory and mental regressions that occur together bring physiological, psychological, and social problems in the elderly $(4,5)$. Physical and mental illnesses associated with the aging process may limit autonomic independence. Losses such as retirement or death of the spouse may also change the role performance. With the decrease in the effectiveness of the older person's life over time, social interaction is affected, and social isolation can be seen $(6,7)$. In a study examining the quality of life of elderly individuals living at home, it was stated that as the participants' functional independence levels decreased, their quality of life also decreased (8). In another study conducted with the elderly living in the nursing home, it was determined that more than half of the elderly living in the nursing home had depression, and depression and quality of life were significantly correlated with each other (9). 
With the increase in the elderly population, more people are at risk of being diagnosed with depression in the future. This situation may cause emotional pain in many individuals over 65 years and their relatives and it also may affect the quality of life negatively. However, early diagnosis and treatment may help to cope with geriatric depression and its consequences (10). In a meta-analysis by Huang et al. (11) (2010), stroke, hearing loss, decreased visual function, heart disease, and chronic lung disease were reported to be factors associated with depression in old age. The presence of chronic physical diseases in elderly individuals and the expectation that their functional independence will be low in elderly individuals may prevent the diagnosis of depression. Therefore, comprehensive physical assessment of these people is particularly important in geriatric depression, in terms of both revealing the main organic causes and identifying potential inflammation factors (12). Geriatric depression is a multifactorial disorder due to the combination of factors (genetic, biological, psychosocial) that cause various degrees of disorder (13). Depression, which causes a significant decrease in the quality of life in the elderly, is a serious condition that may lead to an increased risk of early death (14).

It is known that the physical activity capacity of the individual decreases as the age progresses and muscle atrophy and muscle weakness occur. Regular physical activity is an important requirement for older individuals to maintain overall health (15). In a randomized controlled study examining the effects of the walking program applied to the elderly, it was stated that the walking program positively affected the quality of life and sleep (16). Maintaining the functional independence of elderly individuals at an optimal level is among the goals of health promotion and maintenance (17). The purpose of the nursing approach provided to elderly individuals is to preserve their quality of life and to ensure that they live a supported life with independence as much as possible (18). In this study, we aimed to investigate the relationship between autonomy and depression in individuals older than 65 years and to evaluate the factors affecting these variables.

\section{Methods}

Ethical approval was obtained from the Institutional Review Board (University of Health Sciences Turkey, Gülhane Non-Interventional Ethical Committee, no: 2018-38, date: 06.02.2018). The participants were informed about the research and their consent was obtained. This study was conducted between March and May 2018 at the geriatric outpatient clinic of Gülhane Training and Research Hospital. The sample of the study consisted of 101 subjects over 65 years of age who were mentally intact and had the ability to evaluate the truth. The data were collected by using the "Descriptive Information Form", "(The Functional Autonomy Measurement System-SMAF)" and "Geriatric Depression Scale". Participants were reached after the examination at the outpatient clinic and data collection forms were applied face to face by the researchers.

1. Descriptive Information Form: This form includes data on gender, age, marital status, educational status, having a child, with whom the participants live, being a source of income and having a chronic illness.

2. The Functional Autonomy Measurement System-SMAF: This form evaluates the 29 functions of an individual in the age group of 65 years and above related to activities of daily living, movement, communication, mental functions and instrumental daily living activities. The total inability score of the scale is obtained by adding all function scores. If the total score is less than - 5 , the elderly individual is at risk of losing functional independence (5).

3. Geriatric Depression Scale: The validity and reliability study of the scale was conducted by Ertan et al. (19) in 1997. The self-report scale consists of 30 questions and can be answered as "yes" or "no". In the scale, questions 3, 4, 5, 6, 8, 10, 11, 12, $13,14,16,17,18,20,22,23,24,25,26$ and 28 contain the opposite explanation. In the scoring of the scale, 1 point is given for each response in favor of depression and 0 point is given for the other response, and as a result, total score is accepted as depression score. Scoring of the scale is as follows; 0-10 points were scored as "no depression", 11-13 points were scored as "possible depression", and 14 points and above were scored as "definite depression". The scores that can be obtained from the scale are minimum: 1 and maximum: 30 (19).

\section{Statistical Analysis}

Statistical package for Social Sciences (SPSS Inc., Chicago, IL, USA) 15.0 package program was used to evaluate the data. Mean \pm standard deviation, number and percentage representation were used for descriptive statistics. Differences between groups were analyzed with the Mann-Whitney $U$ test and Kruskal-Wallis test (for two or more comparisons). The Pearson correlation analysis was used to examine the relationship between the parameters.

\section{Results}

Percent of 61.4 the participants were female, $47.5 \%$ were primary school graduates, $47.5 \%$ were $71-80$ years old, $72.3 \%$ were married, and all had children. Percent of 61.4 lived with their spouse, $79.2 \%$ had a source of income, and $88.1 \%$ had a chronic disease. Diseases of patients with chronic disease included diabetes mellitus, hypertension, heart disease, chronic obstructive pulmonary disease, rheumatic diseases, osteoporosis, thyroid, and asthma (Table 1). There was a negative correlation between the mean geriatric depression scale scores and the mean autonomy assessment scale scores of elderly individuals and this relationship was statistically significant $(r=-0.388, p=0.001)$.

The autonomy assessment scale total score average of the participants was $-9.63 \pm-9.17$. There was no statistically 
significant difference between the mean scores of autonomy assessment scale according to gender, income source status, and having a chronic disease. A statistically significant difference was found between the autonomy assessment scale total score averages of the participants according to their educational background $(p<0.05)$. Paired analyses were conducted to determine which groups were the source of this difference. Accordingly, the mean score of illiterate participants $(-15.43 \pm 11.40)$ was lower than that of high school graduates and university graduates $(-4.62 \pm 4.67 ;-7.73 \pm 7.03)$, while the mean score of literate participants $(-15.43 \pm 11.40)$ was lower than those of primary school graduates $-9.67 \pm 9.58)$.

A statistically significant difference was found between the autonomy assessment scale total score means of the participants according to marital status $(p<0.05)$. In order to determine in which groups this difference was caused, dual analyses were performed. According to this, the mean score of the autonomy assessment scale $(-8.90 \pm 6.98)$ was lower than that of the divorced (-1.16 \pm 7.63$)$ and higher than the widow (-12.80 \pm 13.53$)$. In addition, the mean score of autonomy assessment scale

\begin{tabular}{|c|c|c|c|}
\hline \multicolumn{2}{|c|}{ Introductory information } & \multirow{2}{*}{$\begin{array}{l}n \\
62\end{array}$} & \multirow{2}{*}{$\begin{array}{l}\% \\
61.4\end{array}$} \\
\hline \multirow{2}{*}{ Gender } & Female & & \\
\hline & Male & 39 & 38.6 \\
\hline \multirow{5}{*}{ Education } & Not literate & 11 & 10.9 \\
\hline & Literate & 15 & 14.9 \\
\hline & Primary school & 48 & 47.5 \\
\hline & High school & 12 & 11.9 \\
\hline & University & 15 & 14.9 \\
\hline \multirow{3}{*}{ Marital status } & Married & 73 & 72.3 \\
\hline & Divorced & 3 & 3 \\
\hline & Widow & 25 & 24.8 \\
\hline Having a child & Yes & 101 & 100 \\
\hline \multirow{5}{*}{$\begin{array}{l}\text { Who does hel } \\
\text { she live with? }\end{array}$} & Alone & 12 & 11.9 \\
\hline & With partner & 62 & 61.4 \\
\hline & $\begin{array}{l}\text { With partner and } \\
\text { children }\end{array}$ & 9 & 8.9 \\
\hline & With children & 15 & 14.9 \\
\hline & Other & 3 & 3 \\
\hline \multirow{2}{*}{$\begin{array}{l}\text { Income source } \\
\text { status }\end{array}$} & Yes & 80 & 79.2 \\
\hline & No & 21 & 20.8 \\
\hline \multirow{4}{*}{ Age } & $51-60$ & 2 & 2 \\
\hline & $61-70$ & 26 & 25.7 \\
\hline & $71-80$ & 48 & 47.5 \\
\hline & $81-90$ & 25 & 24.8 \\
\hline \multirow{2}{*}{ Chronic illness } & Yes & 89 & 88.1 \\
\hline & No & 12 & 11.9 \\
\hline Total & & 101 & 100 \\
\hline
\end{tabular}

$(-1.16 \pm 7.63)$ of the divorced was higher than that of the widow $(-12.80 \pm 13.53)$. A statistically significant difference was found between the participants' autonomy evaluation scale total score average according to those who lived with the participants $(p<0.05)$. Paired analyses were conducted to determine which groups originated from this difference. According to this, it was seen that the mean scale scores of the participants who preferred the other $(-2.00 \pm 2.00)$ were higher than those of their spouses, spouses and children and those living with their children $(-8.56 \pm 6.91 ;-12.66 \pm 6.81 ;-16.50 \pm 15.95)$. On the other hand, it was found that those living alone $(-6.25 \pm 5.86)$ were higher than those living with their spouse and children $(-12.66 \pm 6.81)$. A statistically significant difference was found between the mean scores of the autonomy assessment scale of the participants by age $(p<0.05)$. In the dual analyses conducted in order to determine which groups displayed this difference, it was seen that the mean score of autonomy assessment scale $(-7.09 \pm 8.01)$ of the age group of $61-70$ years was lower than that of the age group of $81-90$ years $(-12.14 \pm 8.69)$ (Table 2$)$.

The mean total score of geriatric depression was 11.15 \pm 7.25 . There was no statistically significant difference between the mean scores of geriatric depression according to marital status, chronic disease status, the age range of participants, and those with whom they lived $(p>0.05)$. The mean score of geriatric depression scores of female participants $(13.35 \pm 7.56)$ was higher than that of men $(7.66 \pm 5.10)(p \leq 0.005)$. The mean geriatric depression scale scores $(9.95 \pm 6.69)$ were found to be lower than in those without income $(15.76 \pm 7.60)(p<0.05)$. A statistically significant difference was found between the mean scores of the geriatric depression scale of the participants according to their educational status $(p<0.05)$. In the dual analyses conducted to determine from which groups this difference arose from, the total scale mean scores of the illiterate $(12.27 \pm 6.60)$ were lower than those of the literate $(17.93 \pm 7.62)$ and higher than those of primary school, high school and university graduates $(10.56 \pm 6.85 ; 10.33 \pm 5.78 ; 6.13 ; \pm 4.80)$. On the other hand, the mean scores of geriatric depression scale $(17.93 \pm 7.62)$ of the literate participants were higher than those of primary school, high school and university graduates $(10.56 \pm 6.85$; 10.33 \pm 5.78 ; 6.13 \pm 4.80 ) (Table 3).

\section{Discussion}

The mean score of the geriatric depression scale of the individuals over 65 years of age, who participated in the study, was $11.15 \pm 7.25$. This mean score indicates the presence of possible depression. İnel Manav et al. (20) (2018) evaluated the cognitive function level, depression, and quality of life of older people living in a nursing home. In the study, it was stated that the mean score of the geriatric depression scale was 14.92 \pm 4.29 . Similarly, the mean geriatric depression scale score of the elderly who participated in a study (2008) in which the risk of pain and depression was examined in the elderly in the nursing home 
was found to be $14.47 \pm 5.89(21)$. $11-13$ points from the geriatric depression scale are interpreted as "possible depression" and 14 and above points are interpreted as "definitive depression (19). These findings are similar to our results. One of the common psychiatric disorders seen in the elderly population is depressive disorders (22). However, considering depressive symptoms as a part of the nature of old age may be a factor preventing health professionals from being consulted.

In the study, the mean score of geriatric depression scores of female participants was found to be higher than that of men. In the study conducted by Çınar and Kartal (23) with elderly individuals, it was stated that the mean score of Beck Depression Scale that women received was higher than that of men. Kockler and Gender (24) (2002) evaluated the effect of gender differences on the occurrence of depressive symptoms in elderly individuals; women experienced more depressive symptoms than men. These findings are similar to our results and show that women are more likely to experience depression.

\begin{tabular}{|c|c|c|c|}
\hline \multicolumn{2}{|c|}{ Introductory information } & Mean \pm SD & $\begin{array}{l}\text { Statistical } \\
\text { analysis* }\end{array}$ \\
\hline \multirow[t]{2}{*}{ Gender } & Female & $-9.82 \pm 10.34$ & \multirow{2}{*}{$\begin{array}{l}Z=-0.658 \\
p=0.511\end{array}$} \\
\hline & Male & $-9.34 \pm 6.81$ & \\
\hline \multirow{5}{*}{ Education } & Not literate & $-9.63 \pm 6.96$ & \multirow{5}{*}{$\begin{array}{l}x^{2}=10.683 \\
p=0.030\end{array}$} \\
\hline & Literate & $-15.43 \pm 11.40$ & \\
\hline & Primary school & $-9.67 \pm 9.58$ & \\
\hline & High school & $-4.62 \pm 4.67$ & \\
\hline & University & $-7.73 \pm 7.03$ & \\
\hline \multirow{3}{*}{$\begin{array}{l}\text { Marital } \\
\text { status }\end{array}$} & Married & $-8.90 \pm 6.98$ & \multirow{3}{*}{$\begin{array}{l}Z=5.945 \\
p=0.015\end{array}$} \\
\hline & Divorced & $-1.16 \pm 7.63$ & \\
\hline & Widow & $-12.80 \pm 13.53$ & \\
\hline \multirow{5}{*}{$\begin{array}{l}\text { Who does } \\
\text { he/she live } \\
\text { with? }\end{array}$} & Alone & $-6.25 \pm 5.86$ & \multirow{5}{*}{$\begin{array}{l}\chi^{2}=11.138 \\
p=0.025\end{array}$} \\
\hline & With partner & $-8.56 \pm 6.91$ & \\
\hline & $\begin{array}{l}\text { With partner } \\
\text { and children }\end{array}$ & $-12.66 \pm 6.81$ & \\
\hline & With children & $-16.50 \pm 15.95$ & \\
\hline & Other & $-2.00 \pm 2.00$ & \\
\hline \multirow{2}{*}{$\begin{array}{l}\text { Income } \\
\text { source } \\
\text { status }\end{array}$} & Yes & $-9.70 \pm 9.47$ & \multirow{2}{*}{$\begin{array}{l}Z=-0.216 \\
p=0.829\end{array}$} \\
\hline & No & $-9.40 \pm 8.10$ & \\
\hline \multirow{4}{*}{ Age } & $51-60$ & $-3.25 \pm 3.88$ & \multirow{4}{*}{$\begin{array}{l}Z=8.430 \\
p=0.038\end{array}$} \\
\hline & $61-70$ & $-7.09 \pm 8.01$ & \\
\hline & $71-80$ & $-9.97 \pm 9.81$ & \\
\hline & $81-90$ & $-12.14 \pm 8.69$ & \\
\hline \multirow{2}{*}{$\begin{array}{l}\text { Chronic } \\
\text { illness }\end{array}$} & Yes & $-9.67 \pm 8.04$ & \multirow{2}{*}{$\begin{array}{l}Z=-1.476 \\
p=0.140\end{array}$} \\
\hline & No & $-9.33 \pm 15.69$ & \\
\hline Total & & $-9.63 \pm-9.17$ & \\
\hline
\end{tabular}

This may be related to the roles that society attributes to women. In our society, women have responsibilities such as making food, cleaning, child/grandchild care etc. On the other hand, despite the deterioration in the health status of women due to the rootstock aspect, they can strive to fulfill these roles. The combination of these burdens and growing health problems is thought to increase the risk of depression in women.

In our study, it was found that the mean scores of geriatric depression of individuals with low educational level were higher than in those with a high educational level. On the other hand, it was seen that the mean autonomy rating scale scores of the elderly individuals with low educational level were lower than in those with high educational level. According to the results of the research, a negative correlation was found between the autonomy assessment scale scores of elderly individuals and geriatric depression scale scores. Akyol et al. (25) (2010) evaluated the quality of life and depressive symptom level in the geriatric population and stated that individuals with low educational level had higher depression

Table 3. Geriatric depression scale score averages
according to the introductory information of the
participants
participants

\begin{tabular}{|c|c|c|c|}
\hline \multicolumn{2}{|c|}{ Introductory information } & Mean \pm SD & $\begin{array}{l}\text { Statistical } \\
\text { analysis* }\end{array}$ \\
\hline \multirow[t]{2}{*}{ Gender } & Female & $13.35 \pm 7.56$ & \multirow{2}{*}{$\begin{array}{l}Z=-3.574 \\
p=0.001\end{array}$} \\
\hline & Male & $7.66 \pm 5.10$ & \\
\hline \multirow{5}{*}{ Education } & Not literate & $12.27 \pm 6.60$ & \multirow{5}{*}{$\begin{array}{l}\chi^{2}=19.706 \\
p=0.001\end{array}$} \\
\hline & Literate & $17.93 \pm 7.62$ & \\
\hline & Primary school & $10.56 \pm 6.85$ & \\
\hline & High school & $10.33 \pm 5.78$ & \\
\hline & University & $6.13 \pm 4.80$ & \\
\hline \multirow{3}{*}{$\begin{array}{l}\text { Marital } \\
\text { status }\end{array}$} & Marital & $10.46 \pm 7.37$ & \multirow{3}{*}{$\begin{array}{l}Z=1.382 \\
p=0.240\end{array}$} \\
\hline & Divorced & $6.00 \pm 6.08$ & \\
\hline & Widow & $13.80 \pm 6.37$ & \\
\hline \multirow{5}{*}{$\begin{array}{l}\text { Who does } \\
\text { he/she live } \\
\text { with? }\end{array}$} & Alone & $12.91 \pm 5.50$ & \multirow{5}{*}{$\begin{array}{l}\chi^{2}=7.373 \\
p=0.117\end{array}$} \\
\hline & With partner & $9.88 \pm 7.57$ & \\
\hline & $\begin{array}{l}\text { With partner and } \\
\text { children }\end{array}$ & $13.55 \pm 4.97$ & \\
\hline & With children & $12.93 \pm 7.91$ & \\
\hline & Other & $14.33 \pm 6.10$ & \\
\hline \multirow{2}{*}{$\begin{array}{l}\text { Income } \\
\text { source } \\
\text { status }\end{array}$} & Yes & $9.95 \pm 6.69$ & \multirow{2}{*}{$\begin{array}{l}Z=-3.030 \\
t=0.002\end{array}$} \\
\hline & No & $15.76 \pm 7.60$ & \\
\hline \multirow{4}{*}{ Age } & $51-60$ years & $6.00 \pm 4.24$ & \multirow{4}{*}{$\begin{array}{l}Z=1.323 \\
p=0.724\end{array}$} \\
\hline & $61-70$ years & $11.07 \pm 6.84$ & \\
\hline & $71-80$ years & $11.50 \pm 7.76$ & \\
\hline & $81-90$ years & $10.96 \pm 6.99$ & \\
\hline \multirow{2}{*}{$\begin{array}{l}\text { Chronic } \\
\text { illness }\end{array}$} & Yes & $10.97 \pm 7.30$ & \multirow{2}{*}{$\begin{array}{l}Z=-0.802 \\
p=0.423\end{array}$} \\
\hline & No & $12.50 \pm 7.02$ & \\
\hline \multicolumn{2}{|c|}{ Total } & $11.15 \pm 7.25$ & \\
\hline \multicolumn{4}{|c|}{ *Z: Mann-Whitney U test, $\chi^{2}$ : Kruskal-Wallis test, SD: Standard deviation } \\
\hline
\end{tabular}


levels. In a study in Sanliurfa (2016) examining the prevalence of depression and the factors affecting it in the elderly, it was stated that the risk of developing depression was higher in the elderly with a low educational level (26). It is thought that access to information more easily for the elderly with high education level helps them to be more successful in the process of finding solutions to their health problems and thus to be more successful in coping with the stressors they face. As a result, the rate of depression may be lower in individuals with a high educational level. Again, considering the importance of healthy aging of individuals with higher education level, it is thought that they will contribute to increasing the autonomy of lifestyles considering components such as healthy eating and regular exercise.

In our study, it was seen that the mean geriatric depression scale scores of the elderly individuals with a source of income were lower than the non-geriatric depression scale scores. Arslantaş and Ergin (27) (2011) examined loneliness, depression, need for social support and the factors affecting them in individuals aged 50-65 years in Aydın in their study. According to the results of the study, it was found that the presence of depressive symptoms in participants was twice as high in those who did not work in an income-generating job. It is thought that having an income, working in a professional group and maintaining productivity will decrease the incidence of depression in elderly individuals. On the other hand, the lack of a source of income is seen as an obstacle for the individual to reach the necessary means for protection, maintenance and treatment when necessary.

Maintaining mental and physical well-being of elderly individuals is important for healthy aging (28). Difficulties in daily living activities in the elderly may result in the presence of depression and poor quality of life (22). In our study, it was seen that the autonomy scores of elderly individuals decreased with increasing age. It shows that the aging process makes it difficult for the individual to perform daily life activities and functional independence decreases.

It was seen that the autonomy assessment scale scores of married individuals were higher than those of the widows and lower than those of the divorced individuals. When the autonomy scores of the participants with whom they live were examined, the scores of the participants who preferred the other (elderly care homes etc.) were higher than those of their spouses, spouses and children, and those living with their children; it was observed that those living alone were higher than those living with their spouses and children. In addition, Bozkurt and Yılmaz (29) (2016) conducted a study with individuals over 65 years of age and found that autonomy scores of married participants were higher than those of the divorced and widows. Altay et al. (4) (2016) did not find a statistically significant difference between the autonomy of married and unmarried participants in their studies evaluating health perception, quality of life and health- related quality of life of older people aged 60 years and older. Marriage can be seen as an atmosphere where responsibilities and burdens are shared for family members who share the same house, and it can be seen as an environment that increases the responsibilities of women, especially in our society. It is thought that family environment, where domestic violence and conflicts are intense and positive sharing is insufficient, may adversely affect the physical and mental health of the individual. Therefore, it can be thought that the elimination of negative family environment factors of divorced individuals before divorce may have contributed to increase their autonomy levels. For the widows, it is thought that the loss of life and the spouses in which the burdens are shared causes the autonomy to decrease due to the burdens and responsibilities of the loss. It is also thought that the differences in the autonomy scores of the elderly individuals according to their marital status and with whom they live may be due to the differences in the number of participants per group (Table 1).

The fact that the research is single-centered is one of the limitations of the research. Research results can only be generalized to this sample group.

\section{Conclusion}

It was found that individuals over 65 years of age were at risk of losing their functional independence and that they had possible depression. Depression is one of the most frequently observed mental health problems in elderly individuals. Decreased functional independence increases with age and increases the risk of depression in elderly individuals. On the other hand, it is thought that the individual's ability to continue daily activities independently will have a positive effect on mental health. In this respect, it is recommended to increase the initiatives to increase the functional independence level of elderly individuals, to evaluate the functional levels of elderly individuals at regular intervals, to conduct researches that will create awareness about this aspect of care given at home or in hospital and to increase in-service training.

\section{Ethics}

Ethics Committee Approval: Ethical approval was obtained from the Institutional Review Board (University of Health Sciences Turkey, Gülhane Non-Interventional Ethical Committee, no: 2018-38, date: 06.02.2018).

Informed Consent: The participants were informed about the research and their consent was obtained.

Peer-review: Externally peer-reviewed.

\section{Authorship Contributions}

Concept: G.S., Ü.S., Design: G.S., Ü.S., Data Collection or Processing: Ü.S., Analysis or Interpretation: G.S., M.İN., E.Ö., 
Literature Search: G.S., M.I.N., E.Ö., Writing: G.S., Ü.S., M.I.N., E.Ö.

Conflict of Interest: No conflict of interest was declared by the authors.

Financial Disclosure: The authors declared that this study received no financial support.

\section{References}

1. Murayama L, Ahmed I. The geriatric patient. Leigh $\mathrm{H}$, Streltzer J, ed. Handbook of Consultation-Liaison Psychiatry. Springer;2007;341-360.

2. Turkish Statistical Institute (TUIK). Last Accessed Date: 20.01.2020 Available from: www.tuik.gov.tr/PdfGetir. do? $\mathrm{id}=27595$

3. Kenaley, BL, Ten Have T. Integrated telehealth care for chronic illness and depression in geriatric home care patients: the integrated telehealth education and activation of mood (I-TEAM) study. J Am Geriatr Soc. 2014;62:889895.

4. Altay B, Çavuşoğlu F, Çal A. The factors affecting the perception of elderly patients towards health, quality of life and health-related quality of life. TAF Prev Med Bull. 2016;15:181-189.

5. Tuna Z, Şenol Çelik S. The validity and reliability study of the "functional autonomy measurement system" among 65 years and over age group. H.Ü. Sağlık Bilimleri Fakültesi Dergisi. 2012;19:51-61.

6. Öz F. The Last Stage of Life: Elderly The Review of Psychosocial Dimension. Kriz Dergisi. 2012;10:17-28.

7. Karadelioğlu P. The effect of life satisfaction of old persons residing at home and at a nursing home upon the death anxiety level. Haliç University, Insitute of Health Sciences, Master Thesis, 2011.

8. Altuğ F, Yağcı N, Kitiş A, et al. Analyzing of factors affecting the quality of life in elderly at home. Elderly Issues Research Journal. 2009:48-60.

9. Manav Ai, Yeşilot SB, Demirci PY, et al. An evaluation of cognitive function, depression, and quality of life of elderly people living in a nursing home. J Psychiatric Nurs. 2018;9:153-160.

10. Hardy S. Depression in the elderly: a growing problem. Practice Nursing. 2011;22:1-5.

11. Huang $C Q$, Dong BR, Lu ZC, et al. Chronic diseases and risk for depression in old age: a meta-analysis of published literature. Ageing Res Rev. 2010;9:131-141.

12. Herron J, Mitchell A. Depression and antidepressant prescribing in the elderly. Last Accessed Date: 12.12.2019. Available from: https://wileymicrositebuilder.com/ prescriber/wp-content/uploads/sites/23/2018/03/Oldagedepression-Isw.pdf

13. Babatsikou F, Konsolak E, Notara V, et al. Depression in the elderly: a descriptive study of urban and semi-urban greek population. Int J Caring Sci. 2017;10:1286-1295.
14. Depression treatment for the elderly (2015). Last Accessed Date: 11.12.2019. Available from: https://www.sbu.se/ contentassets/091b2eda2ea94eec983300d0d1236e04/ depression-treatment-for-the-elderly.pdf

15. Demirdel S, Şahinoğlu D, Karahan S, et al. Development of the physical activity barriers scale for elderly individuals. Turkish Journal of Geriatrics. 2018;21:607-616.

16. Şekerci YG, Biçer EK. The effect of walking exercise on quality of life and sleep in elderly individuals: randomized controlled study. Turkish Journal of Geriatrics. 2019;22:443453.

17. Bloom H. Preventive Medicine: When to screen for disease in older patients. Geriatrics. 2001;56:41-45.

18. Ercan Şahin, N, Emiroğlu O. Huzurevinde Yaşayan Yaşlılara Uygulanan Anımsama Terapisinin Yaşlıların Yaşam Kalitesine Etkisi. Hacettepe University Institute of Health Sciences, Doctoral Thesis, 2015.

19. Ertan T, Eker E, Şar V. Geriatric depression scale validity and reliability of the turkish elderly population. Arch Neuropsychiatry. 1997;34:62-71.

20. İnel Manav A, Bozdoğan Yeşilot S, Demirci Y, Öztunç G. An evaluation of cognitive function, depression, and quality of life of elderly people living in a nursing home, J Psychiatric Nurs. 2018;9:153-160.

21. Yıldız A, Erol S, Ergun A. Pain and depression risk among elderly people living in a nursing home. Turkish Journal of Geriatrics. 2009;12:156-164.

22. Avatshi A, Grover S. Clinical Practice guidelines for management of depression in elderly. Indian J Psychiatry. 2018;60:S341-S362.

23. Çınar I, Kartal A. Signs of depression in the elderly relationship between depression and sociodemographic characteristics. TAF Prev Med Bull. 2008;7:399-404.

24. Kockler M, Gender HR. Differences of depressive symptoms in depressed and non-depressed elderly persons. Int J. Geriatr Psychiatry. 2002;17:65-72.

25. Akyol Y, Durmuş D, Doğan C, Bek Y, Cantürk F. Quality of life and level of depressive symptoms in the geriatric population. Turk J Rheumatol. 2010;25:165-173.

26. Eriş $H$, Kabalcıoğlu F, Kara B. Şanlıurfa province of depression among the elderly status and factors affecting the city center. Health Care Acad J. 2016;3:119-125.

27. Arslantaş H, Ergin F. Loneliness, depression, social support and related factors in individuals between 50 and 65 years. Turkish Journal of Geriatrics. 2011;14:135-144.

28. Trajkov M, Eminović F, Radovanović S, Dopsaj M, Pavlovic D, Kljajić D. Quality of life and depression in elderly persons engaged in physical activities. Vojnosanit Pregl. 2018;75:177-184.

29. Bozkurt Ü, Yılmaz M. The determination of functional Independence and quality of life of older adults in a nursing home. Int J Caring Sci. 2016;9:198-210. 